\title{
Extramedullary plasmacytoma of the larynx: Literature review and report of a case who subsequently developed acute myeloid leukemia
}

\author{
SHENGLEI GE ${ }^{1}$, GANGHUA ZHU ${ }^{1}$ and $\mathrm{YAN} \mathrm{YI}^{2}$ \\ Departments of ${ }^{1}$ Otolaryngology-Head and Neck Surgery, and ${ }^{2}$ Hematology, The Second Xiangya Hospital, \\ Central South University, Changsha, Hunan 410011, P.R. China
}

Received December 20, 2017; Accepted June 6, 2018

DOI: $10.3892 / 01.2018 .8992$

\begin{abstract}
Extramedullary plasmacytoma (EMP) of the larynx is an extremely rare plasma cell neoplasm outside of the bone marrow, which has not been previously well characterized. A case of laryngeal EMP who developed acute myeloid leukemia (AML) following treatment is described in the present study, as well as an extensive review of the relevant literature. An electronic literature search was performed in PubMed and all pertinent case reports and series in the English language from 1948-October 2017 were identified. A total of 99 cases including the present case were available for review. The mean age of the included patients was 53 years. Supraglottis was the most frequently involved site. The most common treatment modality was radiotherapy alone $(n=41 ; 43 \%)$, followed by a combination of surgery and radiotherapy, then surgery alone. However, for cases published in recent years, the most common treatment modality was surgically based treatment. Overall the treatment outcome was favorable, as a total of $84 \%$ of patients were alive after a mean follow-up of 60 months. However, EMP outcomes for patients with cervical lymphadenopathy or multiple sites involvement were unfavorable with $>40 \%$ of patients relapsing or developing metastasis during the limited follow-up period. A total of 6 subjects developed multiple myeloma and 1 patient converted to AML. The present study provides important insights on the treatment of EMP, which is a rare disease. To the best of our knowledge, this is the first
\end{abstract}

Correspondence to: Professor Yan Yi, Department of Hematology, The Second Xiangya Hospital, Central South University, 139 Renmin Middle Street, Changsha, Hunan 410011, P.R. China

E-mail: yiyancsu@csu.edu.cn

Abbreviations: EMP, extramedullary plasmacytoma; MM, multiple myeloma; AML, acute myeloid leukemia; t-AML, therapy-related acute myeloid leukemia; MN, myeloid neoplasm; t-MNs, therapy-related myeloid neoplasms

Key words: extramedullary plasmacytoma, larynx, treatment modality, outcomes, sequelae, acute myeloid leukemia, multiple myeloma case report of a patient with laryngeal EMP who developed AML following treatment. It is recommended that secondary myeloid neoplasm should be considered besides multiple myeloma during the follow-up period.

\section{Introduction}

Extramedullary plasmacytoma (EMP) is rare, accounting for approximately $3 \%$ of all plasma cell neoplasms. Up to $80 \%$ of EMP cases occur in the head and neck region, particularly in the upper aerodigestive tract, which constitutes less than $1 \%$ of head and neck tumors $(1,2)$. Most head and neck EMPs occur in the sinonasal region, and fewer are found in the larynx $(3,4)$. Although the primary cause of mortality is actually progression to multiple myeloma (MM), conversion to $\mathrm{MM}$ is uncommon (11-30\% incidence). Here, we describe an individual with laryngeal EMP who developed acute myeloid leukemia (AML), rather than MM. Due to the rarity of this tumor, most previous studies focused on a case or case series. In an effort to describe this rare tumor accurately, we made a literature review about its clinical features, diagnosis, treatment modalities, outcomes, and potential sequelae of this disease.

\section{Materials and methods}

Literature review. An electronic literature search was performed in PubMed using the following terms 'plasmacytoma', 'extramedullary plasmacytoma', 'plasma cell tumor' in combination with the terms 'larynx or head and neck'. Articles published from January 1948 to October 2017 were reviewed to identify cases of laryngeal EMP. Nonhuman, duplicates, and non-English language research were excluded. Abstracts were first reviewed to screen articles that discussed cases of laryngeal EMP, and then full-text articles were reviewed for extraction of data. References of the included studies were also examined for additional cases. Individual patient data were collected on age, sex, presentation, site of lesions, treatment course, long-term follow-up and outcomes. Meanwhile, articles for which individual patient data was not available or which focused solely on radiologic, histopathological findings, and diagnosis, were also excluded. 
Statistical analysis. All the recorded treatment modalities are classified in two main categories: Surgically based treatment including surgical resection either alone or with adjuvant radiotherapy, and no-surgically based treatment. Differences between the above two treatment modalities were analyzed by chi-square test. SPSS version 20 statistical software (IBM Corp., Chicago, Illinois) was used, and $\mathrm{P}<0.05$ was considered to indicate a statistically significant difference for all tests.

Ethics statement. This study was approved by the ethics committee of the Second Xiangya Hospital, Central South University (Changsha, China). Written informed consent was obtained from the patient.

\section{Results}

The initial database search yielded 2,022 studies. The articles that were in non-English language, animal research, or duplicate articles were excluded, and 270 studies were left. Next, those unrelated abstracts such as solely focusing on imaging examination or histopathological findings were eliminated, and a total of 127 articles were left for further analysis. The articles in which full-text was unavailable or individual data was incomplete were ruled out. The bibliographies were also examined for additional cases. Finally, 70 studies comprising a total of 98 cases were left for analysis. Therefore, a total of 99 unique patients including our case were identified and the individual patient data collected are given in Table I (5-71). The clinical characteristics for the 99 patients included were summarized in Table II.

Case presentation. A 46-year old male presented to our hospital with cough and sore throat of a 4 month duration. He had a history of hypothyroidism for more than 10 years and received a diagnosis of tuberculosis before presenting to our hospital, but his symptoms persisted after anti-tuberculosis treatment. Fiberoptic laryngoscopy showed swelling of the epiglottis and aryepiglottic fold (Fig. 1). Laboratory findings showed an increased erythrocyte sedimentation rate, other examinations such as anti-tuberculosis antibody test and rheumatoid factors were normal. Chest X-ray was normal. Computed tomography (CT) and magnetic resonance imaging (MRI) of the neck revealed substantial swelling and edema of the epiglottis and enlargement of cervical lymph nodes. Biopsy of these two sites was performed under general anesthesia and microscopic observation showed many well-differentiated plasma cells and lymphocytes infiltration (Fig. 2). Immunohistochemical staining of the laryngeal specimen showed the most cells were positive for CD79a, CD138, CD38, CD5, Ki67, and Lambda, whereas negative for CD20, CD3, CD45RO, Cyclin D1, and PAX-5. Immunohistochemical staining of the cervical lymph nodes showed the most cells were positive for CD38, CD138, CD79a, CD45RO, CD31, Ki67, CD68 and LgG. Gene rearrangement studies indicated monoclonal rearrangements of the immunoglobulin heavy chain. A diagnosis of EMP of the larynx was made and a series of examinations were performed to exclude MM. Laboratory examinations including blood protein electrophoresis, serum immunoglobulins, urinary tests for Bence-Jones proteins were normal. Report of bone marrow biopsy was also within the normal range. In addition to cervical lymphadenopathy, PET-CT and other imaging examinations such as CT and MRI of the chest, abdomen and pelvis showed no distant metastasis. Complete surgical resection was not suitable for this patient, so, he was referred to the Hematology-Oncology Department, and received radiotherapy including 25 sessions of $55 \mathrm{~Gy}$ for laryngeal lesion and cervical metastasis. Meanwhile, adjuvant chemotherapy was also given with thalidomide, vincristine, epirubicin, and cyclophosphamide. His symptoms disappeared after treatment and he had monthly follow-ups.

Five years later, he was readmitted with dizziness that lasted 2 weeks. Complete blood count showed white blood cell $1.94 \times 10^{9} / 1$, red blood cell $1.90 \times 10^{12} / 1$, haemoglobin $66 \mathrm{~g} / 1$, platelet $16 \times 10^{9} / 1$. Bone marrow aspiration revealed a hyperplastic marrow: The granulocytes accounted for $29 \%$, and the myeloblasts accounted for $12.5 \%$; the mononucytes accounted for $32 \%$, and the monoblasts and promonocytes accounted for $21 \%$ (Fig. 3). The blasts were positive for myeloperoxidase stain, and positive for nonspecific esterase, which was inhibited by sodium fluoride. Immunophenotyping of the bone marrow indicated that a group of blast cells (accounting for 4.84\%) were positive for CD13, CD34, CD117, HLA-DR and negative for CD7, CD10, CD15, CD19, CD20, CD22, CD33, CD11b, CD14, CD64; another group of blast cells (accounting for 53.6\%) were positive for CD13, CD33, CD15, CD64, CD11b, and weak positive for CD10 and CD14. These data are consistent with AML French-American-British (FAB) classification M4 subtype. Chromosome karyotype was 46, XY. Then CAG chemotherapy (aclarubicin hydrochloride, low-dose cytarabine and granulocyte colony-stimulating factor) combined with decitabine were administered accordingly and his condition alleviated. This patient is still being followed.

Patient demographics. We found greater higher occurrence in men and this was approximately two times more often than in women. The vocal cords and epiglottis are commonly involved and the main symptom is hoarseness often accompanied by dyspnea, dysphagia, and other symptoms. Supraglottic EMP accounted for the majority of patients with cervical lymphadenopathy. Likely this is due to association with lymphatic vascularity in the supraglottis, which is much denser than in the glottis or subglottis, and this causes greater incidence of lymph node metastasis.

Treatment options. Of 96 recorded treatment modalities, radiotherapy alone was the most common treatment modality, used in 41 cases, followed by a combination of surgery and radiotherapy, and surgery alone. Furthermore, we found that surgically based treatment was the most common treatment modality for cases published in recent years (Table III), despite there was no statistically significant difference between surgically based treatment and no-surgically based treatment modalities reported in these annual intervals $(\mathrm{P}=0.65)$.

Outcomes and sequelaes. Overall treatment outcome was favorable, as a total of $84 \%$ of patients were alive after a mean follow-up of 60 months, independent of treatment modality. However, EMP outcomes for patients with cervical lymphadenopathy or multiple sites involvement were unfavorable, more than $40 \%$ with recurrence or metastasis 


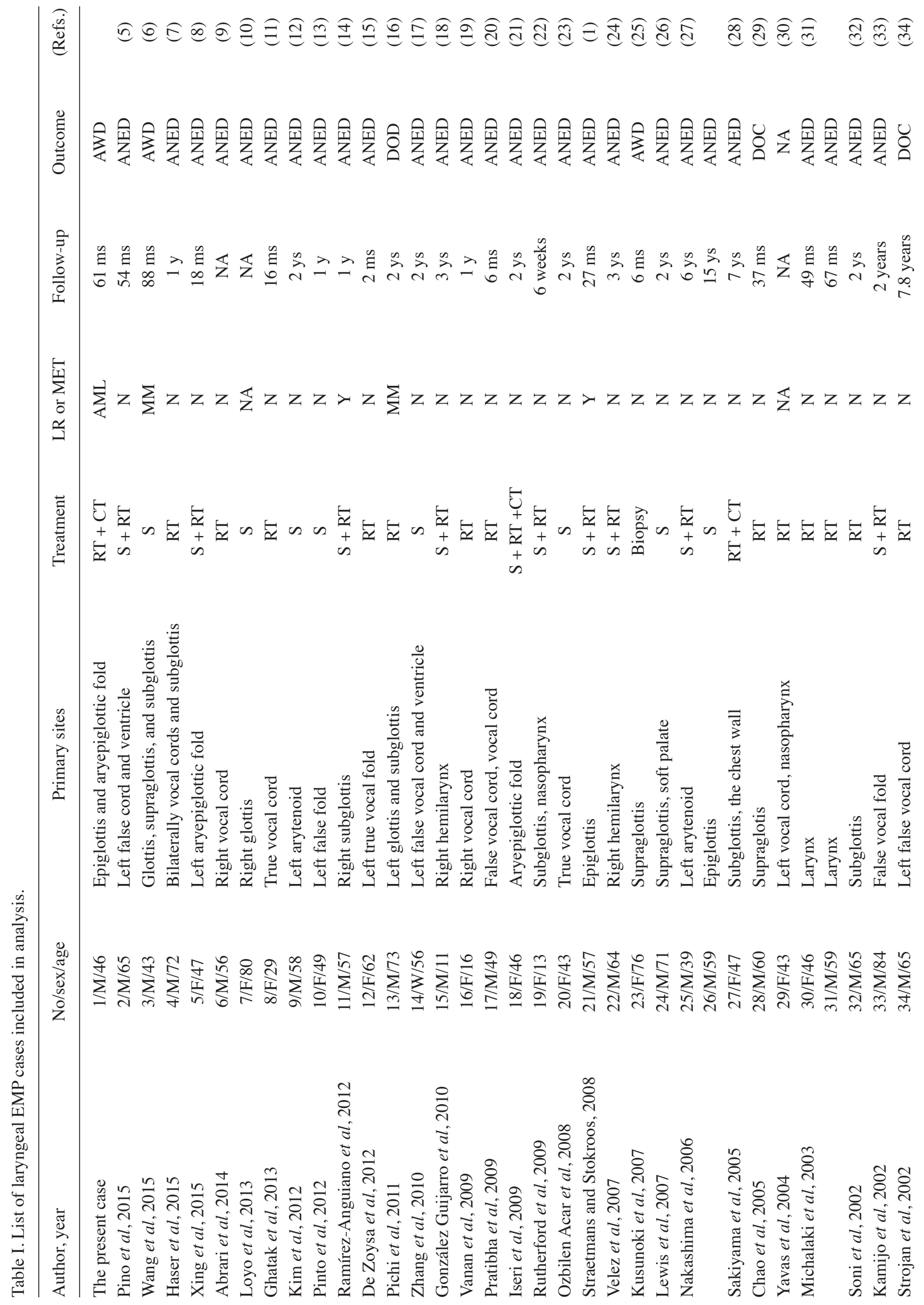




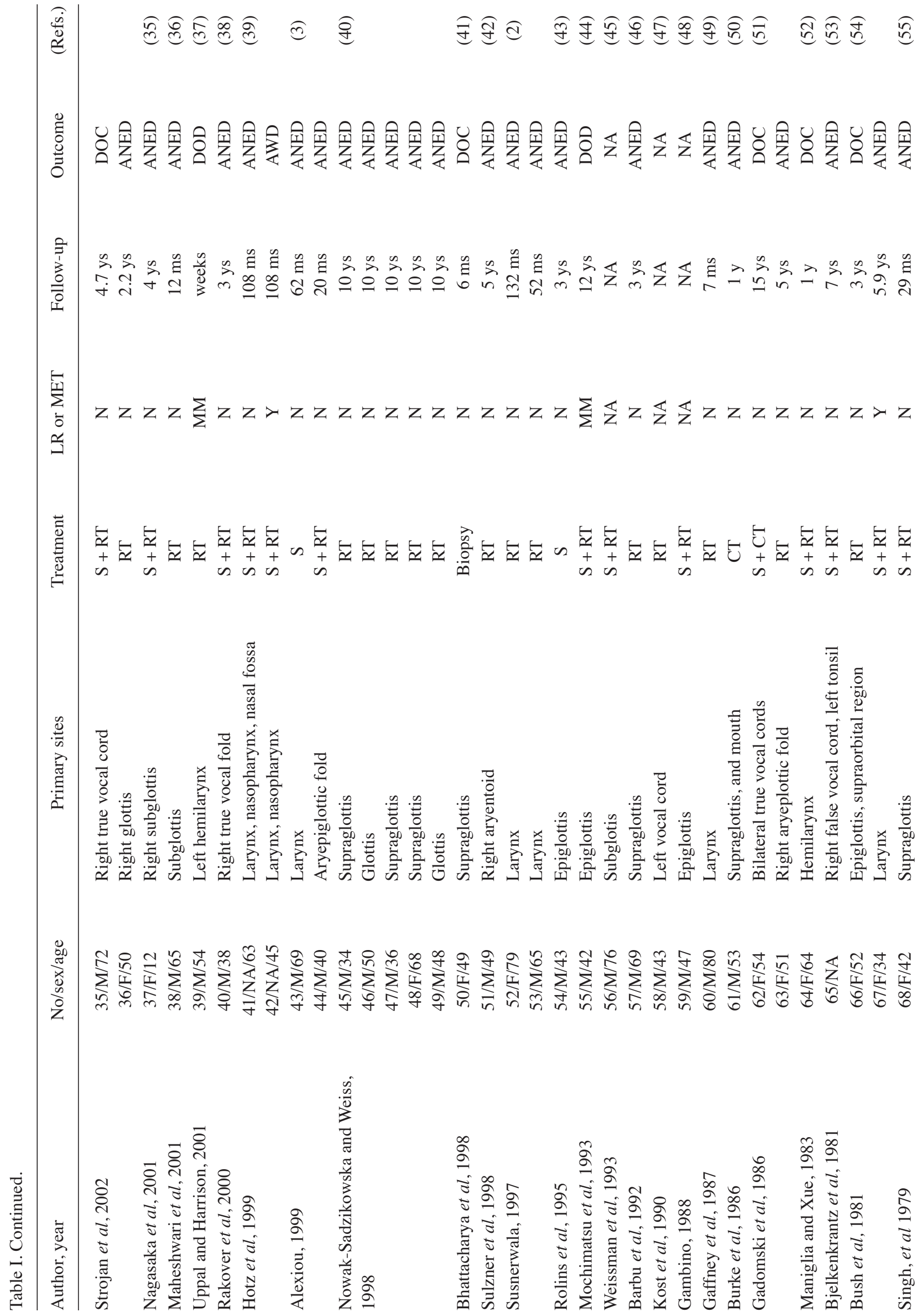




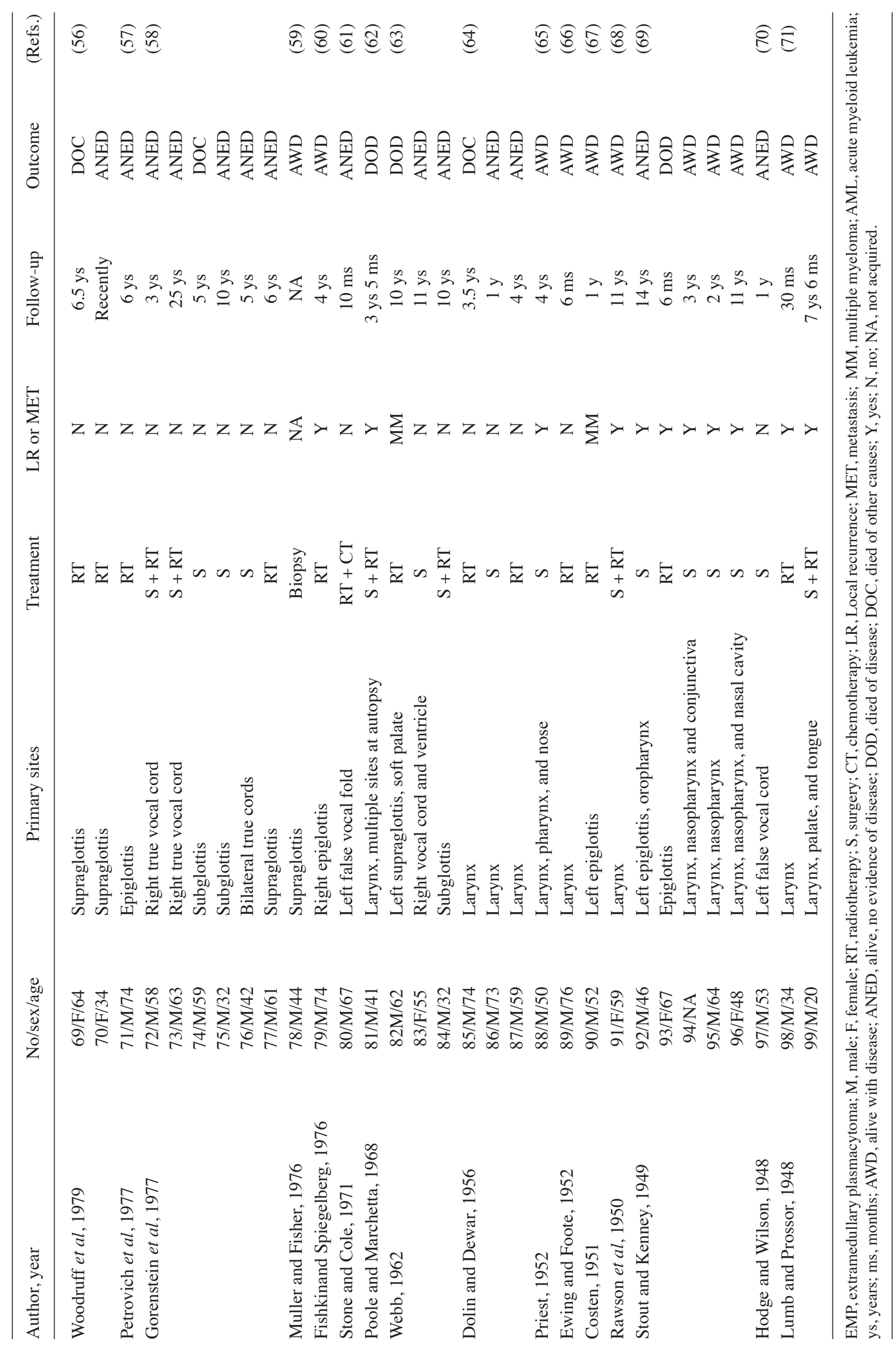


during the limited follow-up period. A total of 21 patients were reported with relapse or metastasis in the clinical course, among which 12 cases were reported that EMP occurred in either multiple sites of the larynx or coexistence with other body sites, and 6 with cervical lymphadenopathy. A total of 6 cases developed MM finally, of which 3 cases occurred in the multiple sites of the larynx, and 2 originated in the supraglottis at the initial visits.

\section{Discussion}

EMP of the larynx is an extremely rare plasma cell neoplasm which constitutes less than $0.2 \%$ of the malignancies in the larynx $(3,4)$. EMP may occur in various sites of the larynx such as the epiglottis, vocal folds, and subglottis. Clinical symptoms are closely related to the location of tumor and the degree of impairment of laryngeal structure. Laryngeal EMP may present different morphologic forms, sometimes a single, smooth polypoid mass, and sometimes diffuse swelling tissue just like our patient. So it is easily misdiagnosed due to the fact that the clinical symptoms and laryngoscope findings are nonspecific compared with other diseases such as laryngeal lymphoma and tuberculosis. Recently, imaging examination has been used more and more widely. For example, CT and MRI of neck may be used to identify the location of tumor and cervical lymphadenopathy, evaluate the involvement of the adjacent structures and curative effect. PET-CT has been used more and more to understand the nature of the lesion and the existence of the distant metastasis. Although radiological findings have acquired much achievement, diagnosis of EMP mainly relies on histopathologic examination by the presence of monoclonal plasma cell hyperplasia. However, the diagnosis could not be made early sometimes by routine pathological observation alone. Thus, immunohistochemistry and immunophenotype are proposed to make a definitive diagnosis or differential diagnosis, for example, most cells may be positive for CD138, CD38, CD79a, and negative for CD20, CD3 (3,4,35). Sometimes, immunoglobulin gene rearrangement analysis is also advised to confirm the diagnosis of EMP.

Given that EMPs are radiosensitive, radiotherapy is traditionally used as first-line treatment for solitary EMP (72). Similarly, single-modality radiotherapy was the most common treatment modality for laryngeal EMP, followed by a combination of surgery and radiotherapy, and surgery alone in our analysis. Recently, surgically based treatment, including surgical resection either alone or with adjuvant radiotherapy was proposed and proved that it could offer better survival outcomes compared to radiotherapy alone (3,73). In contrast, some studies showed no survival benefit for one treatment modality over another, and even recommended that radical surgery should be avoided for EMP (74). So far, the optimal treatment modality for the management of EMP remains controversial. But it has been generally accepted that chemotherapy is not considered to be a first-line therapy option and adjuvant chemotherapy is usually used in patients with disseminated or recurrent disease, that resembles the present case $(3,72)$.

In our review, we found radiotherapy alone was the most common treatment modality for cases published between 1990 and 1999, but for cases reported from 2010 and onward, the
Table II. Clinical features of included cases.

\begin{tabular}{|c|c|}
\hline Characteristics $(\mathrm{n}=95)$ & $\begin{array}{l}\text { Measure, } \\
\text { n (\% total) }\end{array}$ \\
\hline Patient age, mean, median (range), years & $53.3,54(11-80)$ \\
\hline Male, mean $(n=65)$ & 54.9 \\
\hline Female, mean $(n=30)$ & 50 \\
\hline \multicolumn{2}{|l|}{ Symptoms $(n=67)$} \\
\hline Hoarseness & $46(69)$ \\
\hline Dysphonia & $7(10)$ \\
\hline Dyspnea & $13(19)$ \\
\hline Dysphagia & $9(13)$ \\
\hline Stridor & $6(9)$ \\
\hline Cough & $6(9)$ \\
\hline Sore throat & $3(4)$ \\
\hline Hemoptysis & $3(4)$ \\
\hline Laryngeal foreign body sensation & $3(4)$ \\
\hline \multicolumn{2}{|l|}{ Laterality $(\mathrm{n}=41)$} \\
\hline Right & $19(46)$ \\
\hline Left & $17(41)$ \\
\hline Both & $5(12)$ \\
\hline \multicolumn{2}{|l|}{ Primary site $(n=79)$} \\
\hline Glottis & $19(24)$ \\
\hline Supraglottis & $41(52)$ \\
\hline Epiglottis & $12(15)$ \\
\hline Aryepiglottic fold & $4(5)$ \\
\hline Arytenoid & $3(4)$ \\
\hline False vocal cord & $8(10)$ \\
\hline Multiple sites & $2(3)$ \\
\hline Unknown detailed site & $12(15)$ \\
\hline Subglottis & $10(13)$ \\
\hline Hemilarynx or 2-3 parts of the larynx & $9(11)$ \\
\hline \multicolumn{2}{|l|}{ Cervical lymph nodes involvement $(\mathrm{n}=12)$} \\
\hline Glottic patient & $1(8)$ \\
\hline Supraglottic patient & $8(67)$ \\
\hline Hemilaryngeal patient & $1(8)$ \\
\hline Coexistence with other body sites involved & 17 \\
\hline
\end{tabular}

Treatment ( $\mathrm{n}=96)$

Radiotherapy alone

Surgery alone

Chemotherapy alone

28 (29)

Radiotherapy, surgery, and chemotherapy

49.6, $50(30-70)$

Radiotherapy dose, mean, median (range), Gy

No treatment $(n=3)$

Follow-up, mean, median (range), ms ( $=90)$

$60,45(1.5-300)$

Recurrence or metastasis

No recurrence or metastasis

$\mathrm{MM}$

AML

1 (1) 
Table II. Continued.

\begin{tabular}{lc}
\hline Characteristics $(\mathrm{n}=95)$ & $\begin{array}{c}\text { Measure, } \\
\mathrm{n}(\% \text { total })\end{array}$ \\
\hline Outcome $(\mathrm{n}=91)$ & \\
ANED & $63(69)$ \\
AWD & $13(14)$ \\
DOD & $6(7)$ \\
DOC & $9(10)$
\end{tabular}

ms, months; MM, multiple myeloma; AML, acute myeloid leukaemia; ANED, alive, no evidence of disease; AWD, alive with disease; DOD, died of disease; DOC, died of other causes.

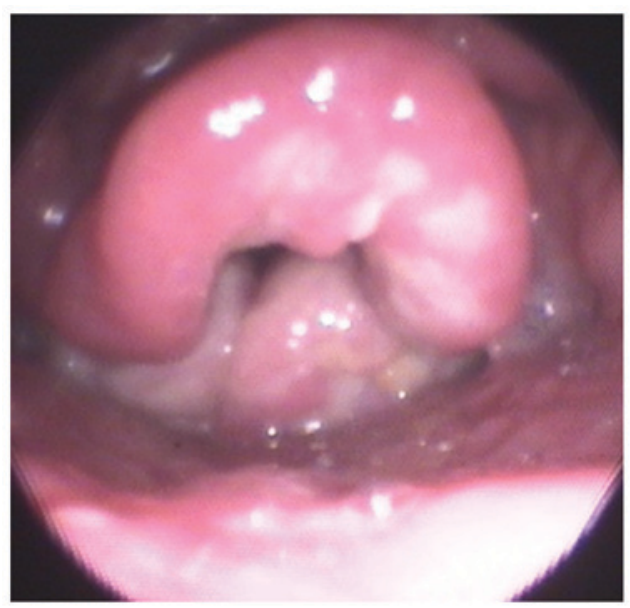

Figure 1. Fiberoptic laryngoscopic view at first presentation.

most common treatment modality was surgically based treatment. There may be some reasons for the shift toward surgical management of small tumors. On the one hand, surgical techniques advance such as laser excision application for laryngeal microsurgery has made it possible to completely resection of lesion through minimally invasive surgery. On the other hand, patients receiving radiotherapy for head and neck EMP had a higher conversion to MM (3), and we found 4 of 6 patients that developed MM received radiotherapy alone in our review, therefore, surgical management of laryngeal EMP should be considered to avoid risk factors for conversion. However, whether it could offer better survival outcomes compared to radiotherapy alone is still to be further studied. Furthermore, patient outcomes may be associated with tumor distribution or cervical lymphadenopathy in addition to treatment modality. For example, more than $40 \%$ of patients with cervical lymphadenopathy or multiple sites involvement were reported with recurrence or metastasis, or even died of disease in our review. In summary, patient outcomes may be affected by many aspects, and management of laryngeal EMP should also be considered on a case-by-case basis. Factors such as tumor location; histological grade; regional lymphadenopathy; feasibility of complete resection; laryngeal function; and potential risk of recurrence or conversion to $\mathrm{MM}$ should be considered when determining the most suitable treatment modality.

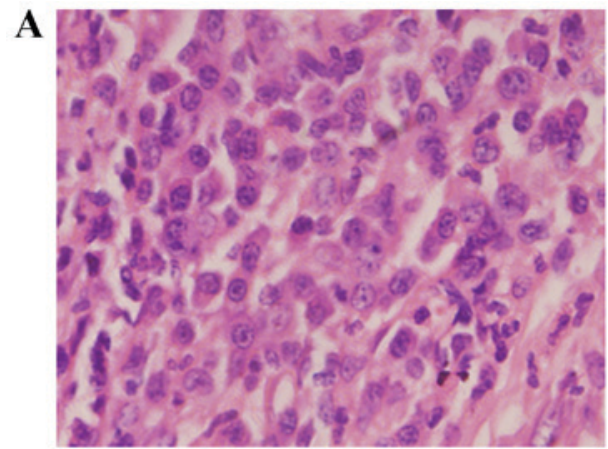

B

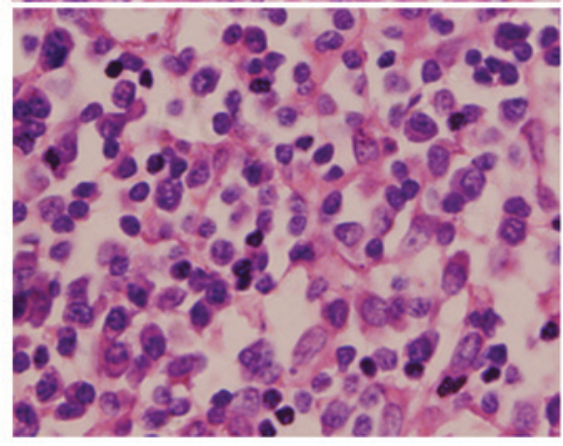

Figure 2. Histopathological examination of the biopsy specimens. Pathological findings revealed a large amount of plasmocyte and lymphocyte infiltration in the (A) laryngeal tumor tissue and (B) cervical lymph nodes (haemotoxylin and eosin staining, magnification, $\mathrm{x} 400$ ).

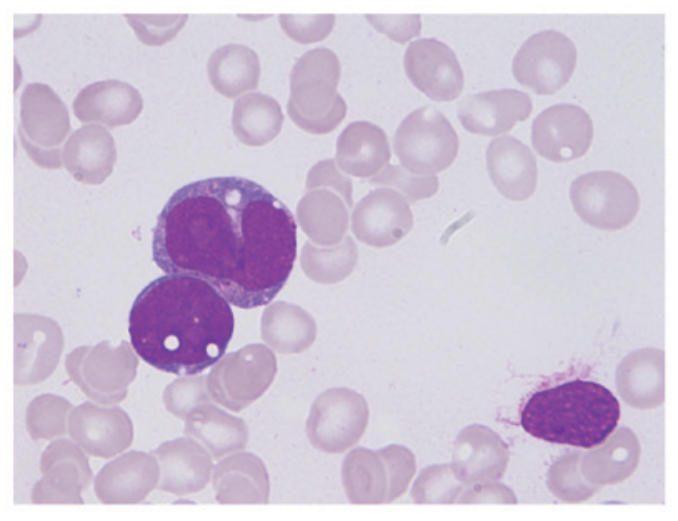

Figure 3. Bone marrow aspirate smear revealed myeloid leukemia cells (Wright-Giemsa staining, oil immersion lens; magnification, x1,000).

EMPs tend to have more favorable outcomes than solitary bone plasmacytomas or MM, and overall survival for 10 years is estimated to exceed $70 \%$ (73). We noted that $84 \%$ of patients in our analysis were alive after a mean follow-up of 60 months. However, we also found that patients with cervical lymphadenopathy, multiple anatomical regions of the larynx or other organ involvement may be prone to relapse or metastasis. The highest risk of conversion to MM is reported to be in the first 2 years after diagnosis, but conversion has also been noted more than 15 years later (4). In our analysis, 3 patients developed MM in the first 2 years, and 1 subject developed MM 12 years later. Although there is debate about high risk factors of conversion to MM, once converted to $\mathrm{MM}$, patients have poor prognosis, and fewer than $10 \%$ of patients survive 10 years (3). Therefore, progression to MM maybe a poor prognostic factor or a 
Table III. Treatment modalities by annual interval.

\begin{tabular}{lcccr}
\hline & \multicolumn{3}{c}{ Years } \\
\cline { 2 - 5 } Treatment modality & $1948-1989$ & $1990-1999$ & $2000-2009$ & $2010-2017$ \\
\hline Surgically based treatment (\%) & $22(55)$ & $7(41)$ & $11(46)$ & $9(60)$ \\
No-surgically based treatment (\%) & $18(45)$ & $10(59)$ & $13(54)$ & $6(40)$ \\
\hline
\end{tabular}

determinant factor for survival. Few patients developed MM in our analysis, and this was less than the expected range. This may be due to the relatively short follow-up for most cases. Therefore, follow-up and regular screening for MM is important.

To the best of our knowledge, this is the first case of laryngeal EMP who subsequently developed AML. On one hand, AML, as the primary second tumor, may occur subsequent to plasma cell myeloma or MM. On the other hand, the occurrence of AML in this case maybe closely related to chemotherapy or radiotherapy, and so it is referred to as therapy-related AML (t-AML). At this time, it is unclear whether this represents an intrinsic predisposition or therapy-related phenomenon (75). Similarly, the pathologic procedure and pathogenesis for this case are unclear and must be elucidated. Even so, this unusual case provides evidence that laryngeal EMP may develop therapy-related myeloid neoplasms (t-MNs) even though this is rare.

In conclusion, we present a comprehensive literature review spanning 60 years to increase awareness of laryngeal EMP. Our findings suggest radiotherapy alone is the most common treatment modality, but surgically based treatment has been the most common treatment modality in recent years. EMP localized to a single region of the larynx may have good outcomes. In addition to MM, t-MNs should be considered during the follow-up period. Due to the inherent limitations of this review, further study about optimal treatment modalities should be considered with randomized controlled clinical trials.

\section{Acknowledgements}

The authors would like to thank Dr Xunqiang Yin (School of Public Health, Central South University, Changsha, China) for his help in the statistical analysis of the paper and Professor Xinming Yang (Department of Otolaryngology-Head and Neck Surgery, The Second Xiangya Hospital, Changsha, China) for his assistance in the drafting and revision of the manuscript.

\section{Funding}

The present study was supported by the National Natural Science Foundation of China (grant nos. 81100360 and 30700940).

\section{Availability of data and materials}

All data generated or analyzed during the present study are included in this published article.

\section{Authors' contributions}

YY conceived this study, interpreted the results and revised the manuscript. SG analyzed the literature data and wrote the manuscript. GZ performed the data collection and analysis. All authors read and approved the final manuscript.

\section{Ethics approval and consent to participate}

This study was approved by the Ethics Committee of The Second Xiangya Hospital, Central South University and written informed consent was obtained from the patient.

\section{Patient consent for publication}

Written informed consent was obtained from the patient consent for the publication of their data and associated images.

\section{Competing interests}

The authors declare that they have no competing interests.

\section{References}

1. Straetmans J and Stokroos R: Extramedullary plasmacytomas in the head and neck region. Eur Arch Otorhinolaryngol 265: $1417-1423,2008$

2. Susnerwala SS, Shanks JH, Banerjee SS, Scarffe JH, Farrington WT and Slevin NJ: Extramedullary plasmacytoma of the head and neck region: Clinicopathological correlation in 25 cases. Br J Cancer 75: 921-927, 1997.

3. Alexiou C, Kau RJ, Dietzfelbinger H, Kremer M, Spiess JC, Schratzenstaller B and Arnold W: Extramedullary plasmacytoma: Tumor occurrence and therapeutic concepts. Cancer 85: 2305-2314, 1999.

4. Bachar G, Goldstein D, Brown D, Tsang R, Lockwood G, Perez-Ordonez B and Irish J: Solitary extramedullary plasmacytoma of the head and neck-long-term outcome analysis of 68 cases. Head Neck 30: 1012-1019, 2008.

5. Pino M, Farri F, Garofalo P, Taranto F, Toso A and Aluffi P: Extramedullary plasmacytoma of the larynx treated by a surgical endoscopic approach and radiotherapy. Case Rep Otolaryngol 2015: 951583, 2015.

6. Wang M, DU J, Zou J and Liu S: Extramedullary plasmacytoma of the cricoid cartilage progressing to multiple myeloma: A case report. Oncol Lett 9: 1764-1766, 2015.

7. Haser GC, Su HK, Pitman MJ and Khorsandi AS: Extramedullary plasmacytoma of the cricoid cartilage with solitary plasmacytoma of the rib. Am J Otolaryngol 36: 598-600, 2015

8. Xing Y, Qiu J, Zhou ML, Zhou SH, Bao YY, Wang QY and Zheng ZJ: Prognostic factors of laryngeal solitary extramedullary plasmacytoma: A case report and review of literature. Int J Clin Exp Pathol 8: 2415-2435, 2015.

9. Abrari A and Bakshi V: Anaplastic: Plasmablastic plasmacytoma of the vocal cord. Indian J Pathol Microbiol 57: 659-660, 2014. 
10. Loyo M, Baras A and Akst LM: Plasmacytoma of the larynx. Am J Otolaryngol 34: 172-175, 2013.

11. Ghatak S, Dutta M, Kundu I and Ganguly RP: Primary solitary extramedullary plasmacytoma involving the true vocal cords in a pregnant woman. Tumori 99: e14-e18, 2013.

12. Kim KS, Yang HS, Park ES and Bae TH: Solitary extramedullary plasmacytoma of the apex of arytenoid: Endoscopic, CT, and pathologic findings. Clin Exp Otorhinolaryngol 5: 107-111, 2012.

13. Pinto JA, Sônego TB, Artico MS, Leal Cde F and Bellotto S: Extramedullary plasmacytoma of the larynx. Int Arch Otorhinolaryngol 16: 410-413, 2012.

14. Ramírez-Anguiano J, Lara-Sánchez H, Martínez-Baños D and Martínez-Benítez B: Extramedullary plasmacytoma of the larynx: A case report of subglottic localization. Case Rep Otolaryngol 2012: 437264, 2012.

15. De Zoysa N, Sandler B, Amonoo-Kuofi K, Swamy R, Kothari P and Mochloulis G: Extramedullary plasmacytoma of the true vocal fold. Ear Nose Throat J 91: E23-E25, 2012.

16. Pichi B, Terenzi V, Covello R and Spriano G: Cricoid-based extramedullary plasmocytoma. J Craniofac Surg 22: 2361-2363, 2011.

17. Zhang XL, Li DQ, Li JJ, Li SS and Yang XM: Synchronous occurrence of extramedullary plasmacytoma and squamous cell carcinoma in situ in the larynx: A case report. Chin J Cancer 29: 1029-1034, 2010.

18. González Guijarro I, Díez González L, Rodriguez Acevedo N and Pallas Pallas E: Extramedullary plasmacytoma of the larynx. A case report. Acta Otorrinolaringol Esp 62: 320-322, 2011 (In Spanish).

19. Vanan I, Redner A, Atlas M, Marin L, Kadkade P, Bandovic J and Jaffe ES: Solitary extramedullary plasmacy toma of the vocal cord in an adolescent. J Clin Oncol 27: e244-e247, 2009.

20. Pratibha CB, Sreenivas V, Babu MK, Rout P and Nayar RC: Plasmacytoma of larynx-a case report. J Voice 23: 735-738, 2009.

21. Iseri M, Ozturk M and Ulubil SA: Synchronous presentation of extramedullary plasmacytoma in the nasopharynx and the larynx. Ear Nose Throat J 88: E9-12, 2009.

22. Rutherford K, Parsons S and Cordes S: Extramedullary plasmacytoma of the larynx in an adolescent: A case report and review of the literature. Ear Nose Throat J 88: E1-E7, 2009.

23. Ozbilen Acar G, Yilmaz S, Güven Güvenc M, Yilmaz M, Ozek H and Tüziner N: Isolated extramedullary plasmacytoma of the true vocal cord. J Otolaryngol Head Neck Surg 37: E129-E132, 2008.

24. Velez D, Hinojar-Gutierrez A, Nam-Cha S and Acevedo-Barbera A: Laryngeal plasmacytoma presenting as amyloid tumour: A case report. Eur Arch Otorhinolaryngol 264: 959-961, 2007.

25. Kusunoki T, Ikeda K, Murata K, Nishida S and Tsubaki M: Extramedullary plasmacytoma of the larynx: a case report from Japan. Ear Nose Throat J 86: 763-764, 2007.

26. Lewis K, Thomas R, Grace R, Moffat C, Manjaly G and Howlett DC: Extramedullary plasmacytomas of the larynx and parapharyngeal space: Imaging and pathologic features. Ear Nose Throat J 86:567-569, 2007.

27. Nakashima T, Matsuda $K$ and Haruta A: Extramedullary plasmacytoma of the larynx. Auris Nasus Larynx 33: 219-222, 2006.

28. Sakiyama S, Kondo K, Mitsuteru Y, Takizawa H, Kenzaki K, Miyoshi T, Abe M, Wakatsuki S and Monden Y: Extramedullary plasmacytoma immunoglobulin D (lambda) in the chest wall and the subglottic region. J Thorac Cardiovasc Surg 129: 1168-1169, 2005.

29. Chao MW, Gibbs P, Wirth A, Quong G, Guiney MJ and Liew KH: Radiotherapy in the management of solitary extramedullary plasmacytoma. Intern Med J 35: 211-215, 2005.

30. Yavas O, Altundag K and Sungur A: Extramedullary plasmacytoma of nasopharynx and larynx: Synchronous presentation. Am J Hematol 75: 264-265, 2004.

31. Michalaki VJ, Hall J, Henk JM, Nutting CM and Harrington KJ: Definitive radiotherapy for extramedullary plasmacytomas of the head and neck. Br J Radiol 76: 738-741, 2003.

32. Soni NK, Trivedi KA, Kumar A, Prajapati JA, Goswami JV, Patel JJ and Patel DD: Solitary extramedullary plasmacytoma-larynx. Indian J Otolaryngol Head Neck Surg 54: 309-310, 2002.

33. Kamijo T, Inagi K, Nakajima M, Motoori T, Tadokoro $\mathrm{K}$ and Nishiyama S: A case of extramedullary plasmacytoma of the larynx. Acta Otolaryngol Suppl: 104-106, 2002.

34. Strojan P, Soba E, Lamovec J and Munda A: Extramedullary plasmacytoma: Clinical and histopathologic study. Int J Radiat Oncol Biol Phys 53: 692-701, 2002.
35. Nagasaka T, Lai R, Kuno K, Nakashima T and Nakashima N: Localized amyloidosis and extramedullary plasmacytoma involving the larynx of a child. Hum Pathol 32: 132-134, 2001.

36. Maheshwari GK, Baboo HA, Gopal U and Shah NM: Extramedullary plasmacytoma of the larynx: A case report. J Indian Med Assoc 99: 267-268, 2001.

37. Uppal HS and Harrison P: Extramedullary plasmacytoma of the larynx presenting with upper airway obstruction in a patient with long-standing IgD myeloma. J Laryngol Otol 115: 745-746, 2001.

38. Rakover Y, Bennett M, David R and Rosen G: Isolated extramedullary plasmacytoma of the true vocal fold. J Laryngol Otol 114: 540-542, 2000.

39. Hotz MA, Schwaab G, Bosq J and Munck JN: Extramedullary solitary plasmacytoma of the head and neck. A clinicopathological study. Ann Otol Rhinol Laryngol 108: 495-500, 1999.

40. Nowak-Sadzikowska J and Weiss M: Extramedullary plasmacytoma of the larynx. Analysis of 5 cases. Eur $\mathrm{J}$ Cancer 34: 1468, 1998.

41. Bhattacharya AK, Han K and Baredes S: Extramedullary plasmacytoma of the head and neck associated with the human immunodeficiency virus. Ear Nose Throat J 77: 61-62, 1998.

42. Sulzner SE, Amdur RJ and Weider DJ: Extramedullary plasmacytoma of the head and neck. Am J Otolaryngol 19: 203-208, 1998.

43. Rolins H, Levin M, Goldberg S, Mody K and Forte FJ: Solitary extramedullary plasmacytoma of the epiglottis: A case report and review of the literature. Otolaryngol Head Neck Surg 112: 754-757, 1995.

44. Mochimatsu I, Tsukuda M, Sawaki S and Nakatani Y: Extramedullary plasmacytoma of the larynx. J Laryngol Otol 107: 1049-1051, 1993.

45. Weissman JL, Myers JN and Kapadia SB: Extramedullary plasmacytoma of the larynx. Am J Otolaryngol 14: 128-131, 1993.

46. Barbu RR, Khan A, Port JL, Abramson A and Gartenhaus WS: Case report: Extramedullary plasmacytoma of the larynx. Comput Med Imaging Graph 16: 359-361, 1992.

47. Kost KM: Plasmacytomas of the larynx. J Otolaryngol 19: 141-146, 1990.

48. Gambino DR: Pathologic quiz case 2. Extramedullary plasmacytoma. Arch Otolaryngol Head Neck Surg 114: 92-93, 95, 1988.

49. Gaffney CC, Dawes PJ and Jackson D: Plasmacytoma of the head and neck. Clin Radiol 38: 385-388, 1987.

50. Burke WA, Merritt CC and Briggaman RA: Disseminated extramedullary plasmacytomas.J Am Acad Dermatol 14:335-339, 1986.

51. Gadomski SP, Zwillenberg D and Choi HY: Non-epidermoid carcinoma of the larynx: The Thomas Jefferson University experience. Otolaryngol Head Neck Surg 95: 558-565, 1986.

52. Maniglia AJ and Xue JW: Plasmacytoma of the larynx. Laryngoscope 93: 741-744, 1983.

53. Bjelkenkrantz K, Lundgren J and Olofsson J: Extramedullary plasmacytoma of the larynx. J Otolaryngol 10: 28-34, 1981.

54. Bush SE, Goffinet DR and Bagshaw MA: Extramedullary plasmacytoma of the head and neck. Radiology 140: 801-805, 1981.

55. Singh B, Lahiri AK and Kakar PK: Extramedullary plasmacytoma. J Laryngol Otol 93: 1239-1244, 1979.

56. Woodruff RK, Whittle JM and Malpas JS: Solitary plasmacytoma. I: Extramedullary soft tissue plasmacytoma. Cancer 43: 2340-2343, 1979.

57. Petrovich Z, Fishkin B, Hittle RE, Acquarelli M and Barton R: Extramedullary plasmacytoma of the upper respiratory passages. Int J Radiat Oncol Biol Phys 2: 723-730, 1977.

58. Gorenstein A, Neel HB, Devine KD and Weiland LH: Solitary extramedullary plasmacytoma of the larynx. Arch Otolaryngol 103: 159-161, 1977.

59. Muller SP and Fisher GH: Pathologic quiz case 1: Extramedullary plasmacytoma of the larynx. Arch Otolaryngol 102: 442-444, 1976.

60. Fishkin BG and Spiegelberg HL: Cervical lymph node metastasis as the first manifestation of localized extramedullary plasmacytoma. Cancer 38: 1641-1644, 1976.

61. Stone HB III and Cole TB: Extramedullary plasmacytomas of the head and neck. South Med J 64: 1386-1388, 1971.

62. Poole AG and Marchetta FC: Extramedullary plasmacytoma of the head and neck. Cancer 22: 14-21, 1968.

63. Webb HE, Harrison EG, Masson JK and Remine WH: Solitary extramedullary myeloma (plasmacytoma) of the upper part of the respiratory tract and oropharynx. Cancer 15: 1142-1155, 1962.

64. Dolin S and Dewar JP: Extramedullary plasmacytoma. Am J Pathol 32: 83-103, 1956 
65. Priest RE: Extramedullary plasma cell tumors of the nose, pharynx and larynx: A case report. Laryngoscope 62: 277-283, 1952 .

66. Ewing MR and Foote FW Jr: Plasma-cell tumors of the mouth and upper air passages. Cancer 5: 499-513, 1952.

67. Costen JB: Plasmocytoma: A case with original lesion of the epiglottis and metastasis to the tibia. Laryngoscope 61: 266-270, 1951.

68. Rawson AJ, Eyler PW and Horn RC Jr: Plasma cell tumors of the upper respiratory tract; a clinico-pathologic study with emphasis on criteria for histologic diagnosis. Am J Pathol 26: 445-461, 1950.

69. Stout AP and Kenney FR: Primary plasma-cell tumors of the upper air passages and oral cavity. Cancer 2: 261-278, 1949.

70. Hodge GE and Wilson T: Extramedullary plasmocytoma of the larynx. Can Med Assoc J 59: 165, 1948.

71. Lumb G and Prossor TM: Plasma cell tumours. J Bone Joint Surg Br 30B: 124-152, 1948

72. D'Aguillo C, Soni RS, Gordhan C, Liu JK, Baredes S and Eloy JA: Sinonasal extramedullary plasmacytoma: A systematic review of 175 patients. Int Forum Allergy Rhinol 4: 156-163, 2014.
73. Gerry D and Lentsch EJ: Epidemiologic evidence of superior outcomes for extramedullary plasmacytoma of the head and neck. Otolaryngol Head Neck Surg 148: 974-981, 2013.

74. Soutar R, Lucraft H, Jackson G, Reece A, Bird J, Low E and Samson D; Guidelines Working Group of the UK Myeloma Forum; British Committee for Standards in Haematology; British Society for Haematology: Guidelines on the diagnosis and management of solitary plasmacytoma of bone and solitary extramedullary plasmacytoma. Br J Haematol 124: 717-726, 2004.

75. Reddi DM, Lu CM, Fedoriw G, Liu YC, Wang FF, Ely S, Boswell EL, Louissaint A Jr, Arcasoy MO, Goodman BK and Wang E: Myeloid neoplasms secondary to plasma cell myeloma: an intrinsic predisposition or therapy-related phenomenon? A clinicopathologic study of 41 cases and correlation of cytogenetic features with treatment regimens. Am J Clin Pathol 138: 855-866, 2012.

(i) $\odot$ This work is licensed under a Creative Commons Attribution-NonCommercial-NoDerivatives 4.0 International (CC BY-NC-ND 4.0) License. 